\title{
High-Order Sliding Mode Control of a DFIG-Based Wind Turbine for Power Maximization and Grid Fault Tolerance
}

\author{
B. Beltran ${ }^{1}$, M.E.H. Benbouzid ${ }^{1}$ and T. Ahmed-Ali ${ }^{2}$ \\ ${ }^{1}$ University of Brest, EA 4325 LBMS - IUT of Brest - Rue de Kergoat - CS 93837, 29238 Brest Cedex 03, France - E-mail: m.benbouzid@ieee.org \\ ${ }^{2}$ University of Caen, UMR CNRS 6072 GREYC - Campus Côte de Nacre, Boulevard du Maréchal Juin, BP 5186, 14032 Caen Cedex, France
}

\begin{abstract}
This paper deals with power extraction maximization and grid fault tolerance of a Doubly-Fed Induction Generator (DFIG)-based Wind Turbine (WT). These variable speed systems have several advantages over the traditional wind turbine operating methods, such as the reduction of the mechanical stress and an increase in the energy capture. To fully exploit this latest advantage, many efforts have been made to develop Maximum Power Point Tracking (MPPT) control schemes. In this context, this paper proposes a highorder sliding mode control. This control strategy presents attractive features such as chattering-free behavior (no extra mechanical stress), finite reaching time, and robustness with respect to external disturbances (grid) and unmodeled dynamics (DFIG and WT). It seems also well adapted for grid disturbance tolerance. The proposed high-order sliding mode control approach has been validated on a 1.5-MW three-blade wind turbine using the wind turbine simulator FAST.
\end{abstract}

Index Terms-Wind turbine, Doubly-Fed Induction Generator (DFIG), power generation, grid fault, high-order sliding mode.

\section{NOMENCLATURE}

$\begin{array}{ll}\text { DFIG } & =\text { Doubly-Fed Induction Generator; } \\ \mathrm{WT} & =\text { Wind Turbine; } \\ \mathrm{HOSM} & =\text { High-Order Sliding Mode; } \\ \mathrm{MPPT} & =\text { Maximum Power Point Tracking; } \\ v & =\text { Wind speed }(\mathrm{m} / \mathrm{sec}) ; \\ \rho & =\text { Air density }\left(\mathrm{kg} / \mathrm{m}^{3}\right) ; \\ R & =\text { Rotor radius }(\mathrm{m}) ; \\ P_{a} & =\text { Aerodynamic power }(\mathrm{W}) ; \\ T_{a} & =\text { Aerodynamic torque }(\mathrm{Nm}) ; \\ \lambda & =\text { Tip speed ratio; } \\ C_{p}(\lambda) & =\text { Power coefficient; } \\ \omega_{m r} & =\text { WT rotor speed }(\mathrm{rad} / \mathrm{sec}) ; \\ \omega_{m g} & =\text { Generator speed }(\mathrm{rad} / \mathrm{sec}) ; \\ T_{g} & =\text { Generator electromagnetic torque }(\mathrm{Nm}) ; \\ J_{t} & =\text { Turbine total inertia }\left(\mathrm{kg} \mathrm{m}^{2}\right) ; \\ K_{t} & =\text { Turbine total external damping }(\mathrm{Nm} / \mathrm{rad} \mathrm{sec}) ; \\ s,(r) & =\text { Stator (rotor) index; } \\ d, q & =\text { Synchronous reference frame index; } \\ V(I) & =\text { Voltage }(\text { Current); } \\ P(Q) & =\text { Active (Reactive) power; } \\ \phi & =\text { Flux; } \\ T_{e m} & =\text { Electromagnetic torque; } \\ R & =\text { Resistance; } \\ L(M) & =\text { Inductance (Mutual inductance); }\end{array}$

$$
\begin{array}{ll}
\sigma & =\text { Leakage coefficient, } \sigma=1-M^{2} / L_{s} L_{r} \\
\theta_{r} & =\text { Rotor position; } \\
\omega_{r}\left(\omega_{s}\right) & =\text { Angular speed (Synchronous speed) } \\
s & =\text { Slip; } \\
p & =\text { Pole pair number. }
\end{array}
$$

\section{INTRODUCTION}

Actually, variable speed wind turbines are continuously increasing their market share, since it is possible to track the changes in wind speed by adapting shaft speed and thus maintaining optimal power generation. The more variable speed wind turbines are investigated, the more it becomes obvious that their behavior is significantly affected by the control strategy used. Typically, they use aerodynamic controls in combination with power electronics to regulate torque, speed, and power. The aerodynamic control systems, usually variable-pitch blades or trailing-edge devices, are expensive and complex, especially when the turbines are larger [1]. This situation provides a motivation to consider alternative control approaches [2].

The main control objective of variable speed wind turbines is power extraction maximization. To reach this goal the turbine tip speed ratio should be maintained at its optimum value despite wind variations. Nevertheless, control is not always aimed at capturing as much energy as possible. In fact, in above rated wind speed, the captured power needs to be limited. Although there are both mechanical and electrical constraints, the more severe ones are commonly on the generator and the converter. Hence, regulation of the power produced by the generator is usually intended and this is the main objective of this paper for a DFIG-based WT using a high-order sliding mode (HOSM) controller that is also intended to achieve grid fault tolerance. Validations are carried out on a 1.5-MW three-blade wind turbine using WT simulator FAST.

\section{WIND TURBINE MODELING}

The global scheme for a grid-connected wind turbine is given in Fig. 1.

\section{A. The Turbine Model}

The turbine modeling is inspired from [3]. In this case, the aerodynamic power $P_{a}$ captured by the wind turbine is given by 


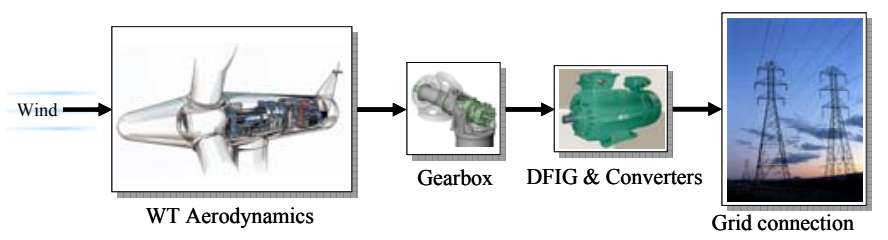

Fig. 1. Wind turbine global scheme.

$P_{a}=\frac{1}{2} \pi \rho R^{2} C_{p}(\lambda) v^{3}$

where $\lambda=\frac{R \omega_{m r}}{v}$

The $C_{p}-\lambda$ characteristics, for different values of the pitch angle $\beta$, are illustrated in Fig. 2. This figure indicates that there is one specific $\lambda$ at which the turbine is most efficient. Normally, a variable speed wind turbine follows the $C_{p \max }$ to capture the maximum power up to the rated speed by varying the rotor speed to keep the system at $\lambda_{\text {opt }}$. Then it operates at the rated power with power regulation during high wind periods by active control of the blade pitch angle or passive regulation based on aerodynamic stall.

The rotor power (aerodynamic power) is also defined by

$$
P_{a}=\omega_{m r} T_{a}
$$

According to [3], the following simplified model is adopted for the turbine (drive train) for control purposes.

$J_{t} \dot{\omega}_{m r}=T_{a}-K_{t} \omega_{m r}-T_{g}$

\section{B. The Generator Model}

The WT adopted generator is the DFIG (Fig. 3) [4] DFIG-based WT will offer several advantages including variable speed operation $( \pm 33 \%$ around the synchronous speed), and four-quadrant active and reactive power capabilities. Such system also results in lower converter costs (typically $25 \%$ of total system power) and lower power losses compared to a system based on a fully fed synchronous generator with full-rated converter. Moreover, the generator is robust and requires little maintenance [5-6].

The control system is usually defined in the synchronous $d-q$ frame fixed to either the stator voltage or the stator flux.

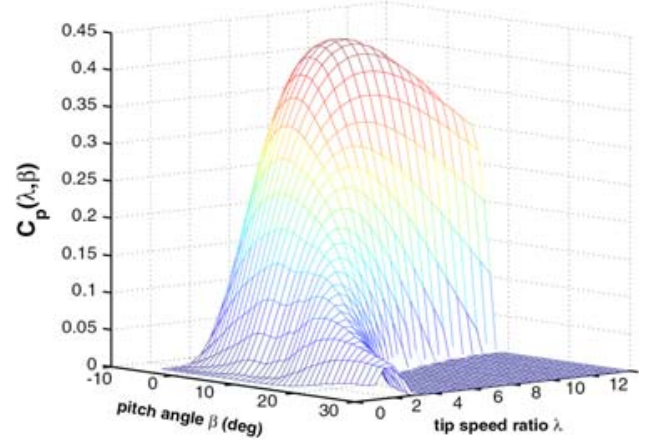

Fig. 2. Wind turbine power coefficient.

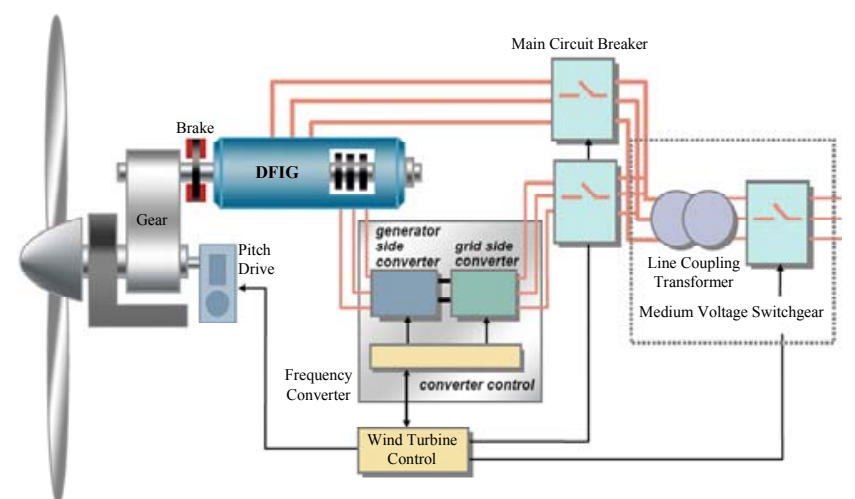

Fig. 3. Schematic diagram of a DFIG-based wind turbine.

For the proposed control strategy, the generator dynamic model written in a synchronously rotating frame $d-q$ is given by (5).

$$
\left\{\begin{array}{l}
V_{s d}=R_{s} I_{s d}+\frac{d \phi_{s d}}{d t}-\omega_{s} \phi_{s q} \\
V_{s q}=R_{s} I_{s q}+\frac{d \phi_{s q}}{d t}+\omega_{s} \phi_{s d} \\
V_{r d}=R_{r} I_{r d}+\frac{d \phi_{r d}}{d t}-\omega_{r} \phi_{r q} \\
V_{r q}=R_{r} I_{r q}+\frac{d \phi_{r q}}{d t}+\omega_{r} \phi_{r d} \\
\phi_{s d}=L_{s} I_{s d}+M I_{r d} \\
\phi_{s q}=L_{s} I_{s q}+M I_{r q} \\
\phi_{r d}=L_{r} I_{r d}+M I_{s d} \\
\phi_{r q}=L_{r} I_{r q}+M I_{s q} \\
T_{e m}=p M\left(I_{r d} I_{s q}-I_{r q} I_{s d}\right)
\end{array}\right.
$$

For simplification purposes, the $q$-axis is aligned with the stator voltage and the stator resistance is neglected [4]. These will lead to (6).

$$
\left\{\begin{array}{l}
\frac{d I_{r d}}{d t}=\frac{1}{\sigma L_{r}}\left(v_{r d}-R_{r} I_{r d}+s \omega_{s} \sigma L_{r} I_{r q}-\frac{M}{L_{s}} \frac{d \phi_{s d}}{d t}\right) \\
\frac{d I_{r q}}{d t}=\frac{1}{\sigma L_{r}}\left(v_{r q}-R_{r} I_{r q}-s \omega_{s} \sigma L_{r} I_{r d}-s \omega_{s} \frac{M}{L_{s}} \phi_{s d}\right) \\
T_{e m}=-p \frac{M}{L_{s}} \phi_{s d} I_{r q}
\end{array}\right.
$$

\section{CONTROL OF THE DFIG-BASED WIND TURBINE}

\section{A. Problem Formulation}

Wind turbines are designed to produce electrical energy as cheaply as possible. Therefore, they are generally designed so that they yield maximum output at wind speeds around 15 $\mathrm{m} / \mathrm{sec}$. In case of stronger winds, it is necessary to waste part of the excess energy of the wind in order to avoid damaging the wind turbine. All wind turbines are therefore designed with some sort of power control. This standard control law keeps the turbine operating at the peak of its $C_{p}$ curve. 
$T_{r e f}=k \omega^{2}$, with $k=\frac{1}{2} \pi \rho R^{5} \frac{C_{p \max }}{\lambda_{o p t}^{3}}$

There is a significant problem with this standard control. Indeed, wind speed fluctuations force the turbine to operate off the peak of its $C_{p}$ curve much of the time. Tight tracing $C_{p \max }$ would lead to high mechanical stress and transfer aerodynamic fluctuations in to the power system. This, however, will result in less energy capture.

To effectively extract wind power while at the same time maintaining safe operation, the wind turbine should be driven according to the following three fundamental operating regions associated with wind speed, maximum allowable rotor speed, and rated power. The three distinct regions are shown by Fig. 4, where $v_{\text {rmax }}$ is the wind speed at which the maximum allowable rotor speed is reached, while $v_{\text {cut-off }}$ is the furling wind speed at which the turbine needs to be shut down for protection. In practice, there are two possible regions of turbine operation, namely the high- and low-speed regions. High speed operation (III) is frequently bounded by the speed limit of the machine. Conversely, regulation in the low-speed region (II) is usually not restricted by speed constraints. However, the system has nonlinear nonminimum phase dynamics in this region. This adverse behavior is an obstacle to perform the regulation task [7].

A common practice in addressing DFIG control problem is to use a linearization approach [8-15]. However, due to the stochastic operating conditions and the inevitable uncertainties inherent in DFIG-based marine current turbines, much of these control methods come at the price of poor system performance and low reliability. Hence the need for nonlinear and robust control to take into account these control problems. Although many modern techniques can be used for this purpose, sliding mode control has proved to be especially appropriate for nonlinear systems, presenting robust features with respect to system parameter uncertainties and external disturbances. For wind turbine control, sliding mode should provide a suitable compromise between conversion efficiency and torque oscillation smoothing [16-19].

In particular, high-order sliding mode is especially appropriate to obtain simple control algorithms with extra features that are the elimination of the chattering phenomenon (main drawback of the traditional sliding mode approach) and a finite time reaching time [20-21]. Up to now, a few secondorder sliding mode control approaches have been introduced for renewable energy applications [22-24].

\section{B. Second-Order Sliding Mode Control Approach}

As the chattering phenomenon is the major drawback of practical implementation of sliding mode control, the most efficient ways to cope with this problem is higher order sliding mode. This technique generalizes the basic sliding mode idea by acting on the higher order time derivatives of the sliding manifold, instead of influencing the first time derivative as it is the case in the standard sliding mode. This operational feature allows to completely mitigating the chattering effect, keeping the main properties of the original approach [24].

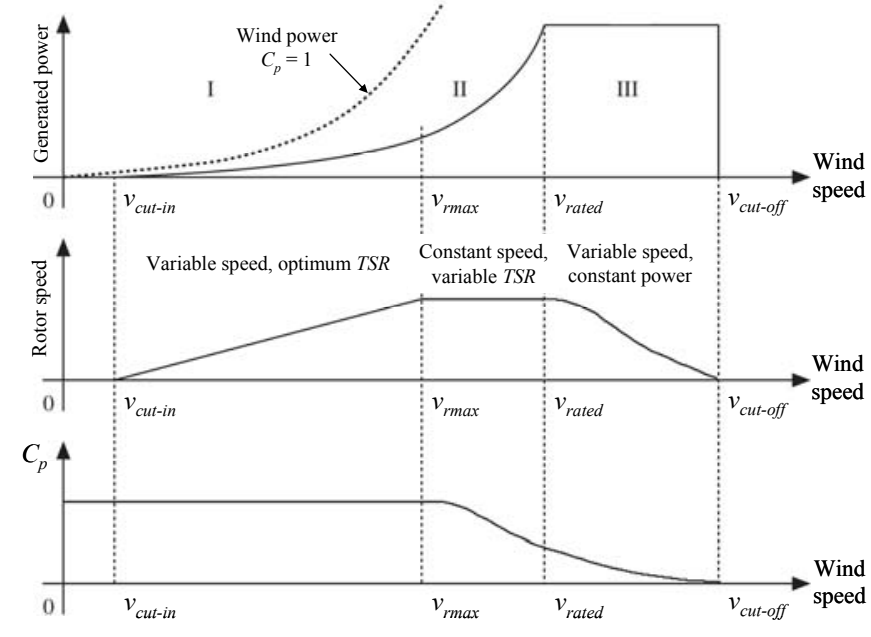

Fig. 4. Wind turbine control regions.

As shown by (8), DFIG control is a coupled one.

$Q_{s}=V_{s q} I_{s d}-V_{s d} I_{s q}$

For a decoupled control, a $d-q$ reference frame attached to the stator flux was used. Therefore, setting the stator flux vector aligned with the $d$-axis, the reactive power can be expressed as

$Q_{s}=\frac{V_{s}}{L_{s}}\left(\phi_{s}-M I_{r d}\right)$

Setting the reactive power to zero will therefore lead to the rotor reference current.

$I_{r d_{-} r e f}=\frac{V_{s}}{\omega_{s} M}$

The DFIG-based WT control objective is to optimize the wind energy capture by tracking the optimal torque $T_{r e f}(7)$.

For these purposes, let us consider the tracking errors

$\left\{\begin{array}{l}e_{I_{r d}}=I_{r d}-I_{r d_{-} r e f} \\ e_{T_{e m}}=T_{e m}-T_{r e f}\end{array}\right.$

Then we will have

$\left\{\begin{array}{l}\dot{e}_{I_{r d}}=\frac{1}{\sigma L_{r}}\left(V_{r d}-R_{r} I_{r d}+s \omega_{s} L_{r} \sigma I_{r q}-\frac{M}{L_{s}} \frac{d \phi_{s d}}{d t}\right)-\dot{I}_{r d_{-} r e f} \\ \dot{e}_{T_{e m}}=-p \frac{M}{\sigma L_{s} L_{r}} \phi_{s}\left(V_{r q}-R_{r} I_{r q}-s \omega_{s} L_{r} \sigma I_{r d}-s \omega_{s} \frac{M}{L_{s}} \phi_{s d}\right)-\dot{T}_{r e f}\end{array}\right.$

If we define the functions $G_{1}$ and $G_{2}$ as follows

$\left\{\begin{array}{l}G_{1}=\frac{1}{\sigma L_{r}}\left(s \omega_{s} \sigma L_{r} I_{r q}-\frac{M}{L_{s}} \frac{d \phi_{s d}}{d t}-R_{r} I_{r d}\right)-\dot{I}_{r d_{-} r e f} \\ G_{2}=-p \frac{M}{\sigma L_{s} L_{r}} \phi_{s}\left(R_{r} I_{r q}-s \omega_{s} \sigma L_{r} I_{r d}-s \omega_{s} \frac{M}{L_{s}} \phi_{s d}\right)-\dot{T}_{r e f}\end{array}\right.$ 
Thus we have

$$
\left\{\begin{array}{l}
\ddot{e}_{I_{r d}}=\frac{1}{\sigma L_{r}} \dot{V}_{r d}+\dot{G}_{1} \\
\ddot{e}_{\Gamma_{e m}}=-p \frac{M}{\sigma L_{s} L_{r}} \phi_{s} \dot{V}_{r q}+\dot{G}_{2}
\end{array}\right.
$$

Now, lets us consider the following second-order sliding mode controller based on the supertwisting algorithm [20].

$\left\{\begin{array}{l}V_{r d}=y_{1}+B_{1}\left|e_{T_{e m}}\right|^{\frac{1}{2}} \operatorname{Sgn}\left(e_{T_{e m}}\right) \\ \dot{y}_{1}=+B_{2} \operatorname{Sgn}\left(e_{T_{e m}}\right) \\ V_{r q}=y_{2}-B_{3}\left|e_{I_{r d}}\right|^{\frac{1}{2}} \operatorname{Sgn}\left(e_{I_{r d}}\right) \\ \dot{y}_{2}=-B_{4} \operatorname{Sgn}\left(e_{I_{r d}}\right)\end{array}\right.$

where the constants $B_{1}, B_{2}, B_{3}$, and $B_{4}(16)$.

$$
\left\{\begin{array}{l}
B_{1}>\frac{\Phi_{2}}{\sigma L_{r}} \\
B_{2}^{2} \geq \frac{4 \Phi_{1}\left(B_{1}+\Phi_{1}\right)}{\sigma^{2} L_{r}^{2}\left(B_{1}-\Phi_{1}\right)} \\
\left|\dot{G}_{1}\right|<\Phi_{1} \\
B_{3}>p \frac{M}{\sigma L_{s} L_{r}} \Phi_{1} \\
B_{4}^{2} \geq \frac{4 \Phi_{2}\left(B_{3}+\Phi_{2}\right)}{\sigma^{2} L_{r}^{2}\left(B_{3}-\Phi_{2}\right)} \\
\left|\dot{G}_{2}\right|<\Phi_{2}
\end{array}\right.
$$

Thus, there exists finite times $t_{T e m}$ and $t_{I r d}$ so as

$$
\begin{cases}I_{r d_{-} r e f}=I_{r d} & \forall t>t_{I_{r d}} \\ T_{r e f}=T_{e m} & \forall t>t_{T_{e m}}\end{cases}
$$

This means that the control objective is achieved. The above proposed DFIG-based WT control strategy is then illustrated by Fig. 5 .

\section{VALIDATION RESULTS}

The proposed high order sliding mode control strategy has been tested for validation using the NREL FAST code [3], [25-26]. The FAST (Fatigue, Aerodynamics, Structures, and Turbulence) code is a comprehensive aeroelastic simulator capable of predicting both the extreme and fatigue loads of two- and three-bladed horizontal-axis wind turbines. This simulator has been chosen for validation because it is proven that the structural model of FAST is of higher fidelity than other codes [27].

An interface has developed between FAST and MatlabSimulink ${ }^{\circledR}$ enabling users to implement advanced turbine controls in Simulink convenient block diagram form (Fig. 6).

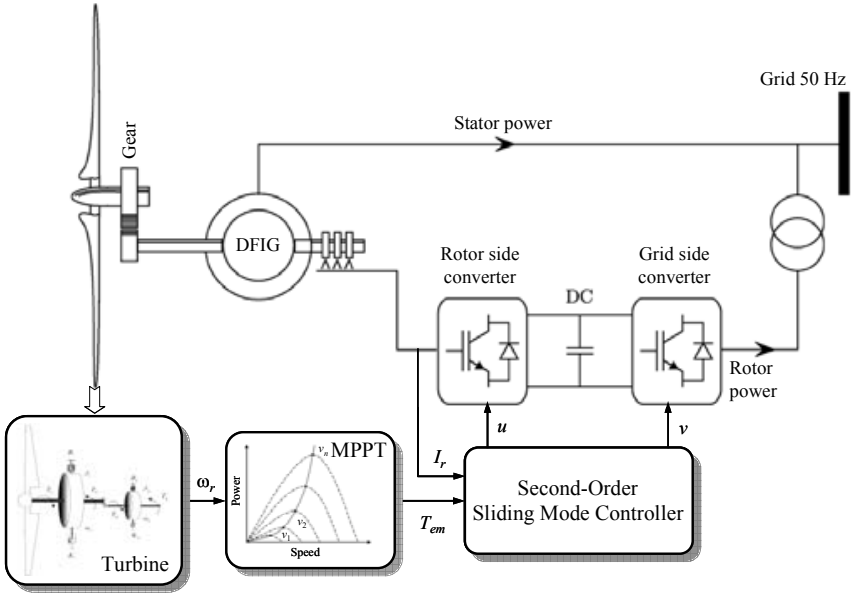

Fig. 5. The proposed control scheme.

Hence, electrical model (DFIG, grid, control system, etc.) designed in the Simulink environment is simulated while making use of the complete nonlinear aerodynamic wind turbine motion equations available in FAST (Fig. 6). This introduces tremendous flexibility in wind turbine controls implementation during simulation.

\section{A. Test Conditions}

Numerical validations, using FAST with MatlabSimulink $^{\circledR}$ have been carried out on the NREL WP 1.5-MW wind turbine which ratings are summarized in Table 1 (Fig. 8) [28]. The DFIG ratings are given in the Appendix.

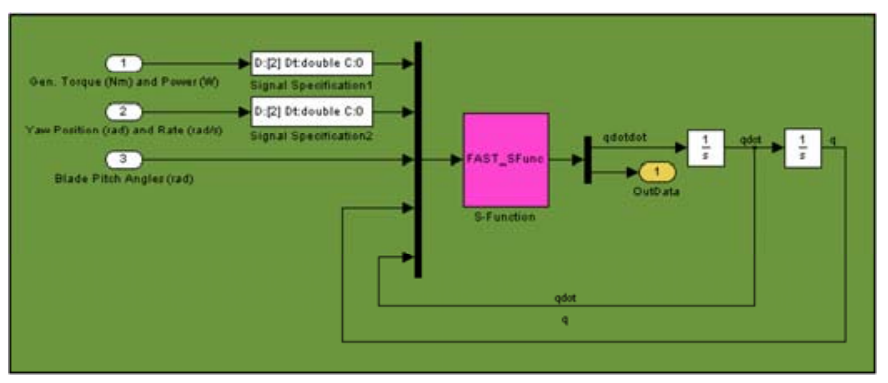

Fig. 6. FAST wind turbine block.

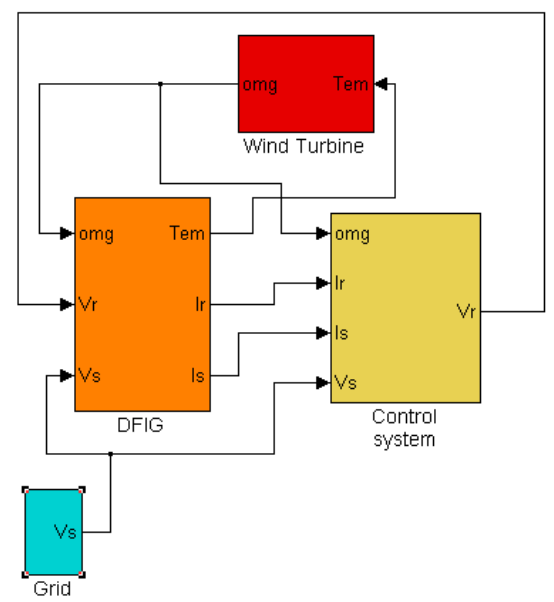

Fig. 7. Simulink model. 


\section{B. Power Maximization Results}

Validation tests were performed using FAST wind data shown by Fig. 9. As clearly shown in Figs. 10 and 11, very good tracking performances are achieved in terms of DFIG rotor current and WT torque with respect to wind fluctuations. The proposed second-order sliding mode control strategy does not induce increased mechanical stress as there are no strong torque variations. Indeed and as expected, the aerodynamic torque remains smooth (Fig. 11).

To assess the effectiveness of the proposed advanced control strategy, it has been compared to more traditional techniques with the same control objectives. The first one is that using the active power as reference [4], [29].

$$
P_{s}=P_{r e f} \Rightarrow I_{r q_{-} r e f}=-\frac{L_{s}}{V_{s} M} P_{r e f}
$$

This approach supposes that the active power is equal to the DFIG electromagnetic power. This approximation drives a difference between the desired torque given by (7) and the generated torque (Fig. 12).

The second assessed approach is the one using the following reference [30].

$$
I_{r q_{-} r e f}=-\frac{L_{s}}{p M \phi_{s}} T_{r e f}
$$

Table 1. Wind Turbine Characteristics.

\begin{tabular}{c|c}
\hline \hline Number of blades & 3 \\
\hline Rotor diameter & $70 \mathrm{~m}$ \\
\hline Hub height & $84.3 \mathrm{~m}$ \\
\hline Rated power & $1.5 \mathrm{MW}$ \\
\hline Turbine total inertia & $4.4532 \times 10^{5} \mathrm{~kg} \mathrm{~m}^{2}$ \\
\hline \hline
\end{tabular}

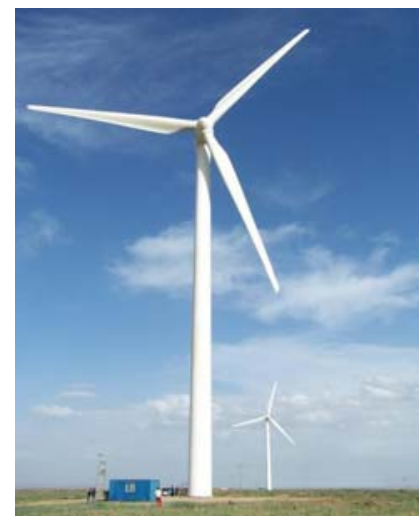

Fig. 8. 1.5-MW wind turbine illustration.

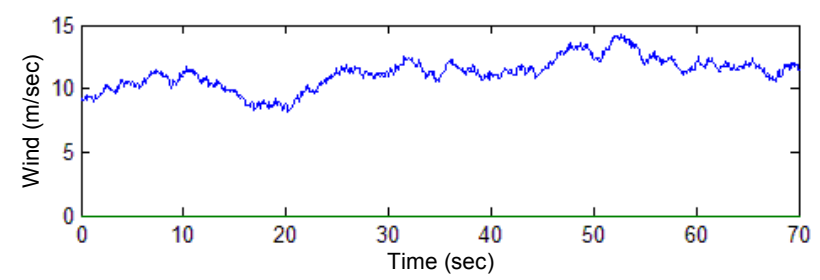

Fig. 9. Wind speed profile.

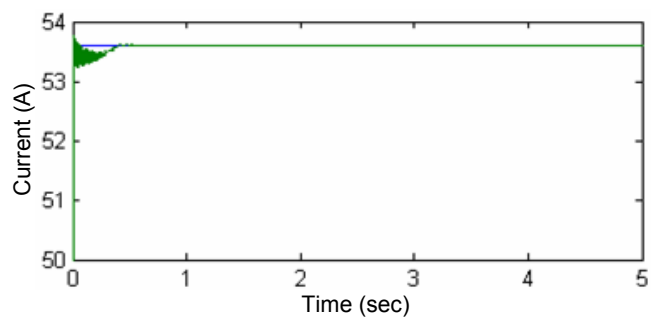

Fig. 10. Current $I_{r d}$ tracking performance: Reference (blue) and real (green).

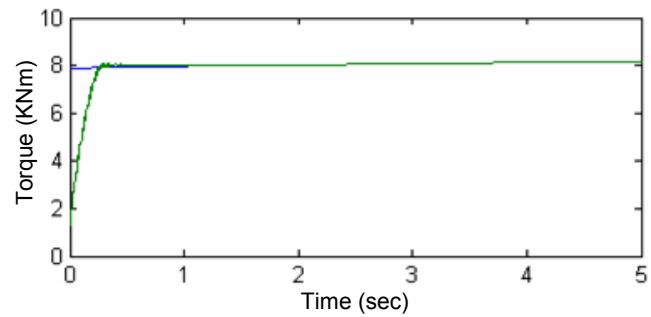

Fig. 11. Torque tracking performance: Reference (blue) and real (green).

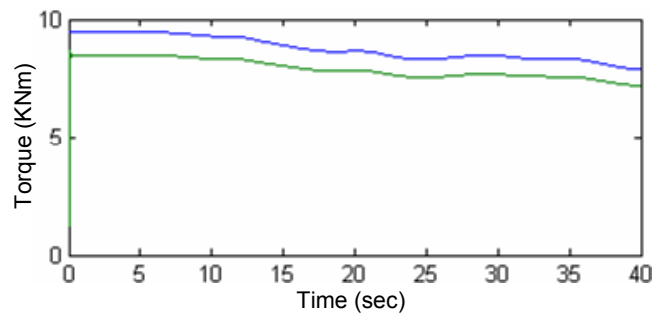

Fig. 12. Torque: Reference (blue) and real (green) [29].

In this case, bad tracking performances are also achieved (Fig. 13). Indeed, the control reference is quite inaccurate due to some adopted simplifications (e.g. a constant stator flux).

In terms of power extraction and maximization, Fig. 14 shows the effectiveness of the proposed second-order sliding mode control with respect to (19) approach. This is mainly due to an inaccurate determination of $k_{\text {opt }}(7)$. Indeed, there is no accurate way to determine $k$, especially since blade aerodynamics can change significantly over time.

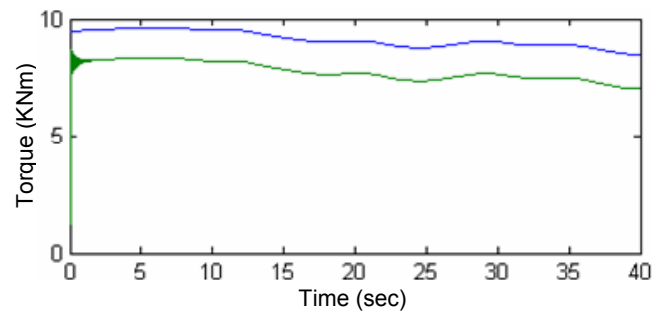

Fig. 13. Torque: Reference (blue) and real (green) [30].

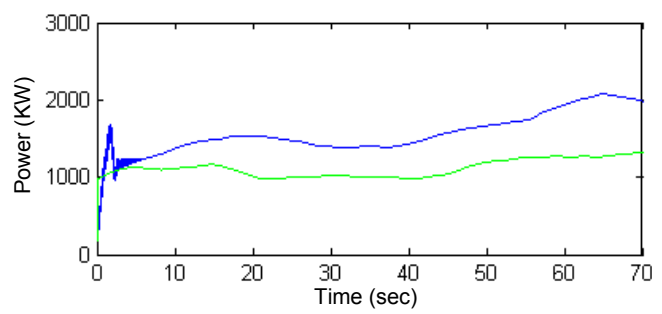

Fig. 14. Generated power: HOSM (blue) and (19) approach (green). 
This fact is therefore an extra justification of the proposed control strategy. If it is assumed that $k$ can be accurately determined via simulations or experiments, Fig. 15 shows that (18) and (19) approaches bad torque tracking can be balanced by the adjustment of $k_{\text {opt }}$. But again, this is a difficult task that is overcome by HOSM.

\section{Grid Fault Tolerance}

1) Context. Fault ride-through specifications listed in modern transmission and distribution grid codes specify that wind-turbine generators must remain connected to electricity networks at voltage levels well below nominal. Achieving reliable operation at greatly reduced voltage levels is proving problematic. A particular problem is that standard controllers designed for reliable operation around nominal voltage levels will not work as designed during low network voltages that can occur during a fault. A consequence of this is greatly increased currents, which may lead to converter failure [31]. Achieving ride-through requirement for DFIG-based WT is a significant technical issue on which turbine manufacturers are working and for which some solutions are proposed [32-36]. Therefore, this part of the paper assesses one of the main features of a sliding mode approach which is robustness against external disturbances (e.g. grid).

2) HOSM assessment. In this case, the ride-through performance of the second-order sliding mode control approach is investigated during unbalanced voltage sags (Fig. 16) [36]. Indeed, when unbalanced sags occur, the main problem is that very high current, torque, and power oscillations appear at double the electrical frequency, forcing a disconnection.

Figure 17 demonstrates successful ride-through performance of the DFIG-based WT using the proposed control technique. Indeed, an almost constant torque is achieved during the unbalanced voltage sags. Moreover, good tracking performances are also achieved in terms of DFIG rotor current (Fig. 18).

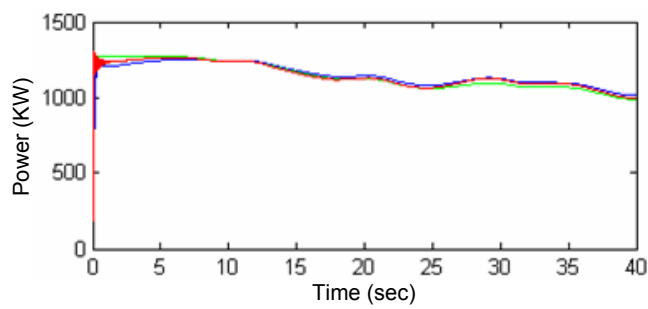

Fig. 15. Generated power: HOSM (blue),

(18), and (19) approaches (green and red) with $k_{\text {opt }}$ adjustment.

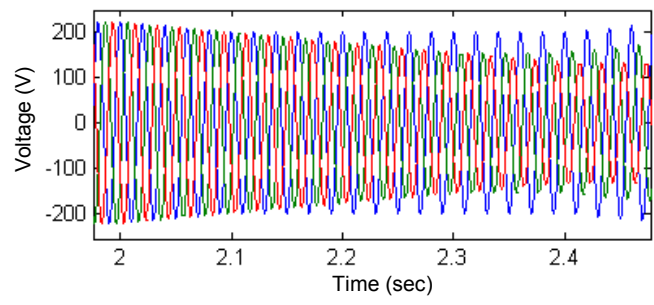

Fig. 16. Grid voltage.

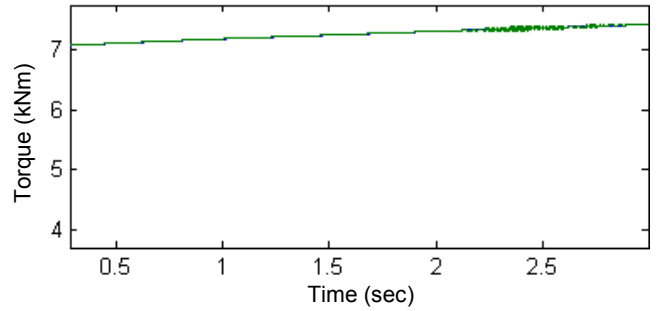

Fig. 17. Torque tracking performance during unbalanced voltage sags: Reference (blue) and real (green).

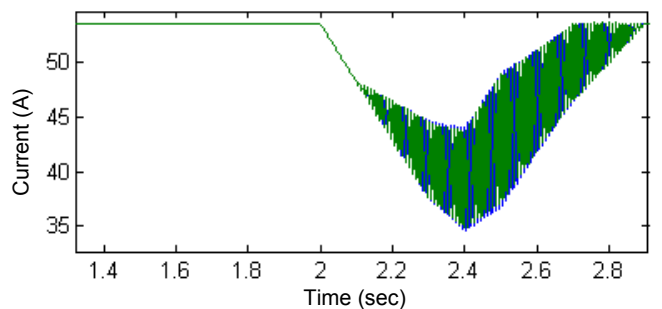

Fig. 18. Current $I_{r d}$ tracking performance during unbalanced voltage sags: Reference (blue) and real (green).

\section{CONCLUSION}

This paper dealt with a second-order sliding mode control of DFIG-based wind turbine. Its main features are a chattering-free behavior, a finite reaching time, and robustness with respect to external disturbances (grid) and unmodeled dynamics (DFIG and WT).

The proposed control strategy has been tested using the NREL FAST code on 1.5-MW three-blade DFIG-based wind turbine. The obtained results clearly show the effectiveness of the second-order sliding mode approach in terms of maximization of the extracted power. Moreover, it does not induce increased mechanical stress on the wind turbine drive train as there are no strong torque variations.

Grid fault tolerance has also been investigated using highorder sliding mode control in case of unbalanced voltage sags. The obtained results clearly indicate successful ride-through performance of the DFIG-based wind turbine.

\section{APPENDIX}

PARAMETERS OF THE USED DFIG

$R_{s}=0.005 \Omega, L_{s}=0.407 \mathrm{mH}, R_{r}=0.0089 \Omega, L_{r}=0.299 \mathrm{mH}$ $M=0.0016 \mathrm{mH}, p=2$

\section{REFERENCES}

[1] R. Thresher et al., "The status and future of wind energy technology," IEEE Power \& Energy Magazine, vol. 5, no. 6, pp. 34-46, November/December 2007.

[2] F.D. Bianchi et al., Wind Turbine Control Systems. Principles, Modelling and Gain Scheduling Design. London: Springer 2007.

[3] B. Beltran et al., "Sliding mode power control of variable speed wind energy conversion systems," IEEE Trans. Energy Conversion, vol. 23, no. 2, pp. 551-558, June 2008.

[4] S. Müller et al., "Doubly fed induction generator systems," IEEE Industry Applications Magazine, vol. 8, n³, pp. 26-33, May-June 2002.

[5] M.E.H. Benbouzid et al., "The state of the art of generators for wind energy conversion systems," in Proceedings of ICEM'06, Chania, Crete Island, Greece, September 2006. 
[6] J.M. Carrasco et al., "Power-electronic systems for the grid integration of renewable energy sources: A survey," IEEE Trans. Industrial Electronics, vol. 53, n4, pp. 1002-1016, June 2006.

[7] T. Senjyu et al., "Output power leveling of wind turbine Generator for all operating regions by pitch angle control," IEEE Trans. Energy Conversion, vol. 21, n², pp. 467-475, June 2006.

[8] R. Pena et al., "Sensorless control of doubly-fed induction generators using a rotor-current-based MRAS observer," IEEE Trans. Industrial Electronics, vol. 55, $\mathrm{n}^{\circ} 1$, pp. 330-339, January 2008.

[9] A.K. Jain et al., "Wound rotor induction generator with sensorless control and integrated active filter for feeding nonlinear loads in a stand-alone grid," IEEE Trans. Industrial Electronics, vol. 55, n¹, pp. 330-339, January 2008.

[10] F. Bonnet et al., "Dual direct torque control of doubly fed induction machine," IEEE Trans. Industrial Electronics, vol. 54, n5, pp. 2482 2490, October 2007.

[11] G. Iwanski et al., "Sensorless direct voltage control of the stand-alone slip-ring induction generator," IEEE Trans. Industrial Electronics, vol 54, n², pp. 1237-1239, April 2007.

[12] G. Tapia et al., "Proportional-integral regulator-based approach to wind farm reactive power management for secondary voltage control," IEEE Trans. Energy Conversion, vol. 22, n², pp. 488-498, June 2007.

[13] L. Xu et al., "Direct active and reactive power control of DFIG for wind energy generation," IEEE Trans. Energy Conversion, vol. 21, n³, pp. 750-758, September 2006.

[14] R. Cardenas et al., "MRAS observer for sensorless control of standalone doubly fed induction generators," IEEE Trans. Energy Conversion, vol. 20, n4, pp. 710-718, December 2005.

[15] A. Mirecki et al., "Architecture complexity and energy efficiency of small wind turbines," IEEE Trans. Industrial Electronics, vol. 54, no. 1, pp. 660-670, February 2007.

[16] I. Munteanu et al., "Energy-reliability optimization of wind energy conversion systems by sliding mode control," IEEE Trans. Energy Conversion, vol. 23, n³, pp. 975-985, September 2008.

[17] B. Beltran et al., "Sliding mode power control of variable-speed wind energy conversion systems," IEEE Trans. Energy Conversion, vol. 23, $\mathrm{n}^{\circ} 2$, pp. 551-558, June 2008 .

[18] J. Matas et al., "Feedback linearization of direct-drive synchronous wind-turbines via a sliding mode approach," IEEE Trans. Power Electronics, vol. 23, n³, pp. 1093-1103, May 2008.

[19] F. Valenciaga et al., "Variable structure control of a wind energy conversion system based on a brushless doubly fed reluctance generator," IEEE Trans. Energy Conversion, vol. 22, n², pp. 499-506, June 2008.

[20] A. Levant et al., "Integral high-order sliding modes," IEEE Trans. Automatic Control, vol. 52, n7, pp. 1278-1282, July 2007.

[21] L. Fridman and A. Levant, Sliding Mode Control in Engineering, Marcel Dekker, Inc., 2002, Chap. 3 Higher Order Sliding Modes, pp. 53-101.
[22] S.E. Ben Elghali et al., "High-order sliding mode control of DFIGbased marine current turbine", in Proceedings of the IEEE IECON'08, Orlando, Florida (USA), pp. 1228-1233, November 2008.

[23] B. Beltran et al., "High-order sliding mode control of variable speed wind turbines," IEEE Trans. Industrial Electronics, IEEE Xplore 10.1109/TIE.2008.2006949, 2009.

[24] F. Valenciaga et al., "High-order sliding control for a wind energy conversion system based on a permanent magnet synchronous generator," IEEE Trans. Energy Conversion, vol. 23, n³, pp. 860-867, September 2008

[25] http://wind.nrel.gov/designcodes/simulators/fast/. (Last accessed December 2008)

[26] R. Fadaeinedjad et al., "Simulation of a wind turbine with doubly fed induction generator by FAST and Simulink," IEEE Trans. Energy Conversion, vol. 23, no. 2, pp. 690-700, June 2008

[27] A. Manjock, "Design codes FAST and ADAMS ${ }^{\circledR}$ for load calculations of onshore wind turbines," Report No.72042, Germanischer Lloyd WindEnergie GmbH, Hamburg (Germany), May 26, 2005.

[28] M.M. Hand et al., "Advanced control design and field testing for wind turbines at the National Renewable Energy Laboratory," NREL/CP-50036118, May 2004

[29] F. Poitiers et al., "Advanced control of a doubly-fed induction generator for wind energy conversion," Electr. Power Syst. Res., doi:10.1016/j.epsr.2009.01.007, 2009.

[30] R. Cardenas et al., "Sensorless vector control of induction machines for variable-speed wind energy applications," IEEE Trans. Energy Conversion, vol. 19, n¹, pp. 196-205, March 2004.

[31] A. Mullane et al., "Wind-turbine fault ride-through enhancement," IEEE Trans. Power Systems, vol. 20, n²4, pp. 1929-1937, November 2005.

[32] Y. Zhou et al. "Operation of grid-connected DFIG under unbalanced grid voltage Condition," IEEE Trans. Energy Conversion, vol. 24, n¹, pp. 240-246, March 2009.

[33] J. $\mathrm{Hu}$ et al., "Improved control of DFIG systems during network unbalance using PI-R current regulators," IEEE Trans. Industrial Electronics, vol. 56, n², pp. 439-451, February 2009.

[34] D. Santos-Martin et al., "Direct power control applied to doubly fed induction generator under unbalanced grid voltage conditions," IEEE Trans. Power Electronics, vol. 23, n5, pp. 2328-2336, September 2008.

[35] P.S. Flannery et al., "A fault tolerant doubly fed induction generator wind turbine using a parallel grid side rectifier and series grid side converter," IEEE Trans. Power Electronics, vol. 23, n³, pp. 1126 1135, May 2008

[36] O. Gomis-Bellmunt et al., "Ride-through control of a doubly fed induction generator under unbalanced voltage sags," IEEE Trans. Energy Conversion, vol. 23, n²4, pp. 1036-1045, December 2008. 